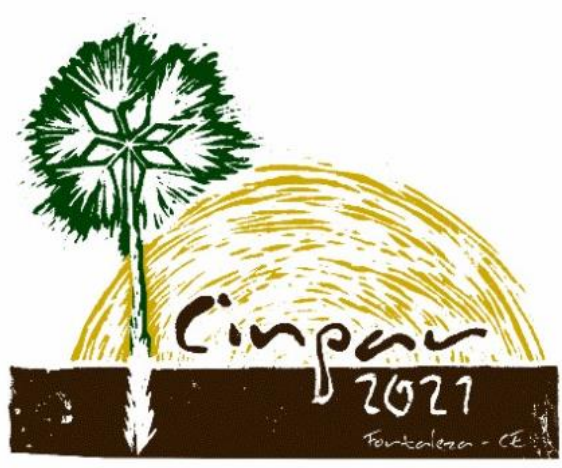

XVII Congresso Internacional sobre Patologia e

Reabilitação das Construções

XVII Congreso Internacional sobre Patología y

Rehabilitación de las Construcciones

XVII International Conference on Pathology and Constructions Rehabilitation

FORTALEZA (Brasil), 3 a 5 de junho de 2021

https://doi.org/10.4322/CINPAR.2021.001

\title{
Análise das manifestações patológicas em edificação unifamiliar de Teresina-PI utilizando a metodologia do Grau de Deterioração da Estrutura (GDE/UnB)
}

\section{Analysis of pathological manifestations in single-family building in Teresina-PI using the Degree of Structure Deterioration methodology (GDE/UnB)}

\author{
Mariana SILVA ${ }^{1}$, Francisco MARQUES NETO ${ }^{2}$, Ítallo Esrom ALVES ${ }^{3}$, Wallison Carlos BARBOSA ${ }^{4}$ \\ ${ }^{1}$ Universidade Federal do Piauí, Teresina, Brasil, marimohana@hotmail.com1 \\ 2 Universidade Federal do Piauí, Teresina, Brasil, netinho19.civil@gmail.com2 \\ ${ }^{3}$ Universidade Federal do Piauí, Teresina, Brasil, italoesrom@gmail.com3 \\ ${ }^{4}$ Universidade Federal do Piauí, Teresina, Brasil, wallcsb@ufpi.edu.br4
}

\begin{abstract}
Resumo: As patologias correspondem ao conjunto de deformidades da construção civil, as quais podem comprometer a segurança da estrutura e reduzir drasticamente a sua vida útil. Este problema afeta diversas edificações localizadas na cidade de Teresina-PI, podendo ocasionar consequências graves para a estabilidade estrutural das edificações. Este trabalho objetiva identificar e analisar as manifestações patológicas presentes em uma edificação unifamiliar na cidade de Teresina, indicando as causas e intensidade das mesmas. Ademais, este estudo visa à apresentação do diagnóstico das manifestações patológicas e à elaboração de intervenções capazes de solucionar o problema, garantindo o desempenho satisfatório da edificação quanto ao uso, estética e segurança. Os objetivos foram alcançados através da utilização da Metodologia do Grau de Deterioração da Estrutura (GDE/Unb), que quantifica o grau de deterioração de cada elemento estrutural que compõe a edificação, assim como da estrutura como um todo, utilizando parâmetros que levam em consideração o grau de agressividade ambiental, a frequência e a intensidade das manifestações patológicas existentes.
\end{abstract}

Palavras-chave: Patologias, Construção Civil, Edificação, Estrutura, Segurança.

Abstract: Pathologies are a set of civil construction's deformities, which can compromise the security of the structure and reduce drastically your life span. This problem affect many buildings located in the city of Teresina-PI, which can occasion serious consequences for the structural stability of buildings. This work aims to identify and analyse the pathological manifestations present in a single-family building in the city of Teresina, indicating the causes and intensity of them. Furthermore, this study aims to present the diagnosis of pathological manifestations and to develop interventions capable of solving the problem, guaranteeing the satisfactory performance of the building in terms of use, aesthetics and security. The goals were achieved through the use of the Methodology of the Degree of Deterioration of the structure (GDE/UnB), which quantifies the deterioration degree of each structural element that makes up the building, as well as the structure as a whole, using parameters that take into account the degree of environmental aggressiveness, the frequency and the intensity of existing pathological manifestations.

Keywords: Pathologies, Civil Construction, Building, Structure, Security.

\section{Introdução}


A cidade de Teresina, por ser o município mais populoso do estado do Piauí, atrai novos moradores de diversas cidades e estados, já que possui centros de educação de grande destaque nos níveis médio e superior, é considerada um importante centro de atendimento médico do Brasil, além de outros serviços de qualidade que o município oferece. Entretanto, observa-se que uma quantidade significativa de edificações residenciais e comerciais tem apresentado manifestações patológicas preocupantes.

Um fator de grande relevância na evolução das patologias é a falta de manutenção periódica nas estruturas, motivada pela quantidade reduzida de normas que regulamentam os programas de manutenção e pela crença equivocada de que as estruturas de concreto possuem durabilidade infinita. Contudo, o desempenho de uma estrutura não é definido apenas pelas cargas que a mesma recebe, mas também, é o resultado da sua interação com os agentes externos, os quais a tornam suscetível à deterioração.

Segundo Rostam (1991), o maior obstáculo não é a deterioração, mas a forma como ela ocorre e com qual intensidade. Este argumento corrobora a necessidade da realização de inspeções que permitam identificar, precocemente, manifestações patológicas, como forma de garantir que as estruturas desempenhem, de modo eficiente, a função para a qual foram projetadas.

Sitter (1984), propôs a "Lei dos 5", a qual demonstra que a evolução dos custos de reparo em estruturas ocorre segundo uma projeção geométrica de razão 5 , isto é, toda medida tomada ainda durante a fase de projeto implica em um custo 125 vezes inferior a uma medida tomada durante a fase de manutenção corretiva. Portanto, quanto mais cedo os reparos forem realizados, menores serão os custos.

Dessa forma, a importância deste trabalho está na necessidade de expandir o acervo bibliográfico a respeito das manifestações patológicas em estruturas de concreto armado, através da realização de um levantamento e análise das patologias presentes em uma edificação residencial unifamiliar na cidade de Teresina-PI, assim como a identificação das suas causas e elaboração de medidas de intervenção que solucionem este problema e garantam a manutenção dessas estruturas, com baixos custos de reparo.

\section{Metodologia}

A metodologia a ser empregada para a análise da estrutura de concreto armado se baseia no trabalho de Castro (1994), estruturado no Programa de Pós-Graduação em Estruturas e Construção Civil da Universidade de Brasília (PECC-UnB) e aprimorado por Lopes (1998), Boldo (2002) e Fonseca (2007), os quais tornaram a sua aplicação mais abrangente e prática. $O$ método consiste na realização de uma análise dos projetos estrutural e arquitetônico e de uma inspeção visual na edificação onde as patologias se encontram, com o objetivo de obter informações e capturar imagens que permitam o cálculo do grau de deterioração dos elementos estruturais.

Além disso, tal metodologia também permite classificar os elementos quanto à necessidade de intervenção, norteando os profissionais durante a tomada de decisões. Ademais, outros estudos foram realizados acerca das patologias com o objetivo de analisar os outros subsistemas da edificação, tais como, forros e alvenarias de vedação.

\section{Análise das manifestações patológicas na residência}

A edificação residencial estudada foi construída no ano de 2012, em concreto armado, sendo constituída apenas de pavimento térreo. A residência é composta por 1 garagem, 1 banheiro social, 1 sala de estar, 1 cozinha, 1 despensa, 1 área de serviço, 1 suíte e 3 quartos, totalizando uma área construída de $110 \mathrm{~m}^{2}$. Durante a execução da sua estrutura, alguns erros foram cometidos, como a falta de um profissional qualificado para o acompanhamento da obra, a não execução do telhado metálico previsto em projeto e a não impermeabilização adequada das lajes. Os elementos estruturais que a compõe estão dispostos de acordo com a Figura 1. 


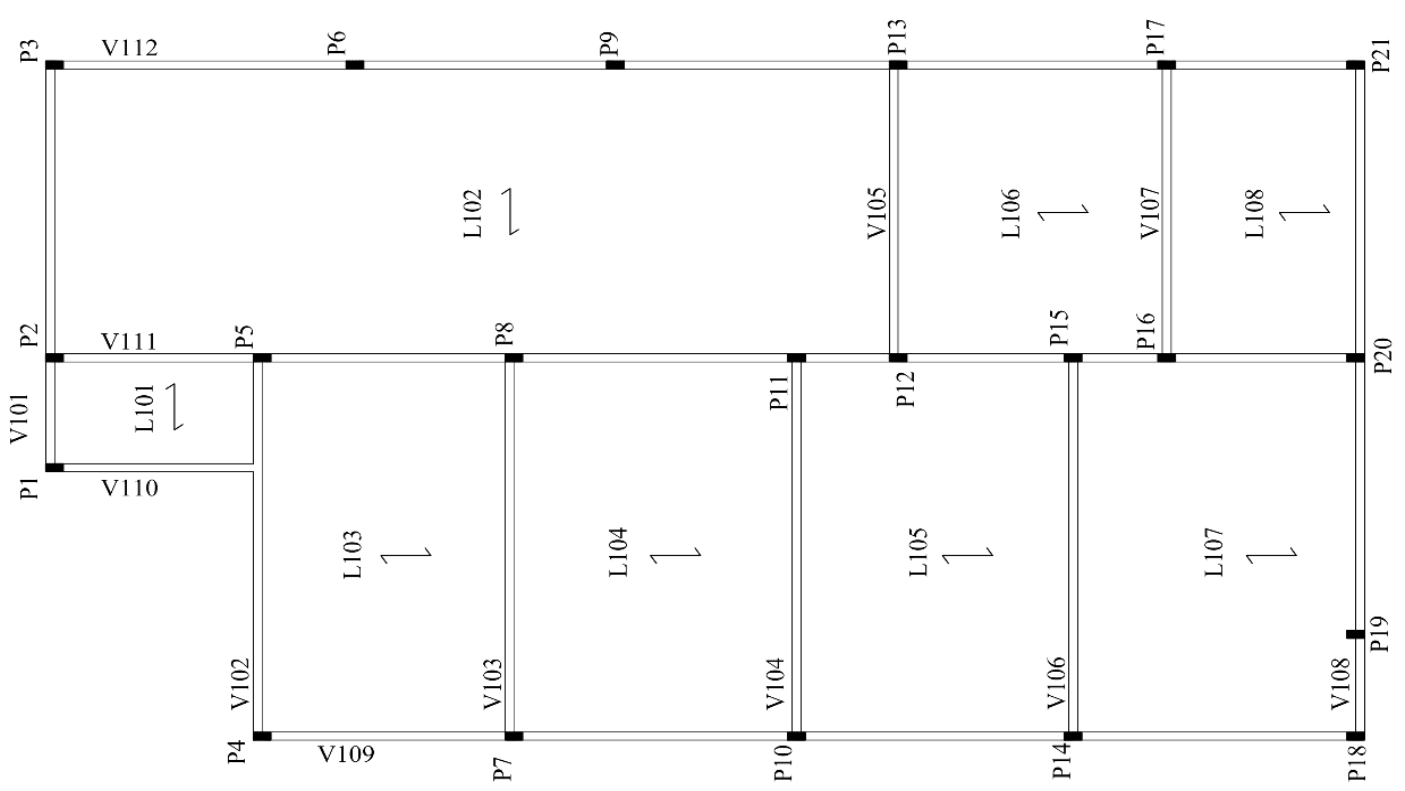

Figura 1 - Planta de fôrma

\subsection{Exposição e corrosão da armadura e desagregação do concreto}

Nas Figuras 2 e 3, nota-se a desagregação do concreto na laje treliçada da sala de estar, que corresponde à desintegração do material, comprometendo e reduzindo as propriedades ligantes dos aglomerantes, que permitem a união dos grãos de agregados. A NBR 6118/2014 (tabela 7.2) sugere que as seções de concreto apresentem cobrimento mínimo de $25 \mathrm{~mm}$, para Classe de Agressividade Ambiental II em lajes, garantindo a proteção das seções de aço. Assim, foi possível observar inúmeros sinais de deficiência estrutural nas lajes devido à insuficiência dos cobrimentos, ocasionando a exposição e corrosão da armadura, assim como o comprometimento da estética, desempenho e vida útil da estrutura.

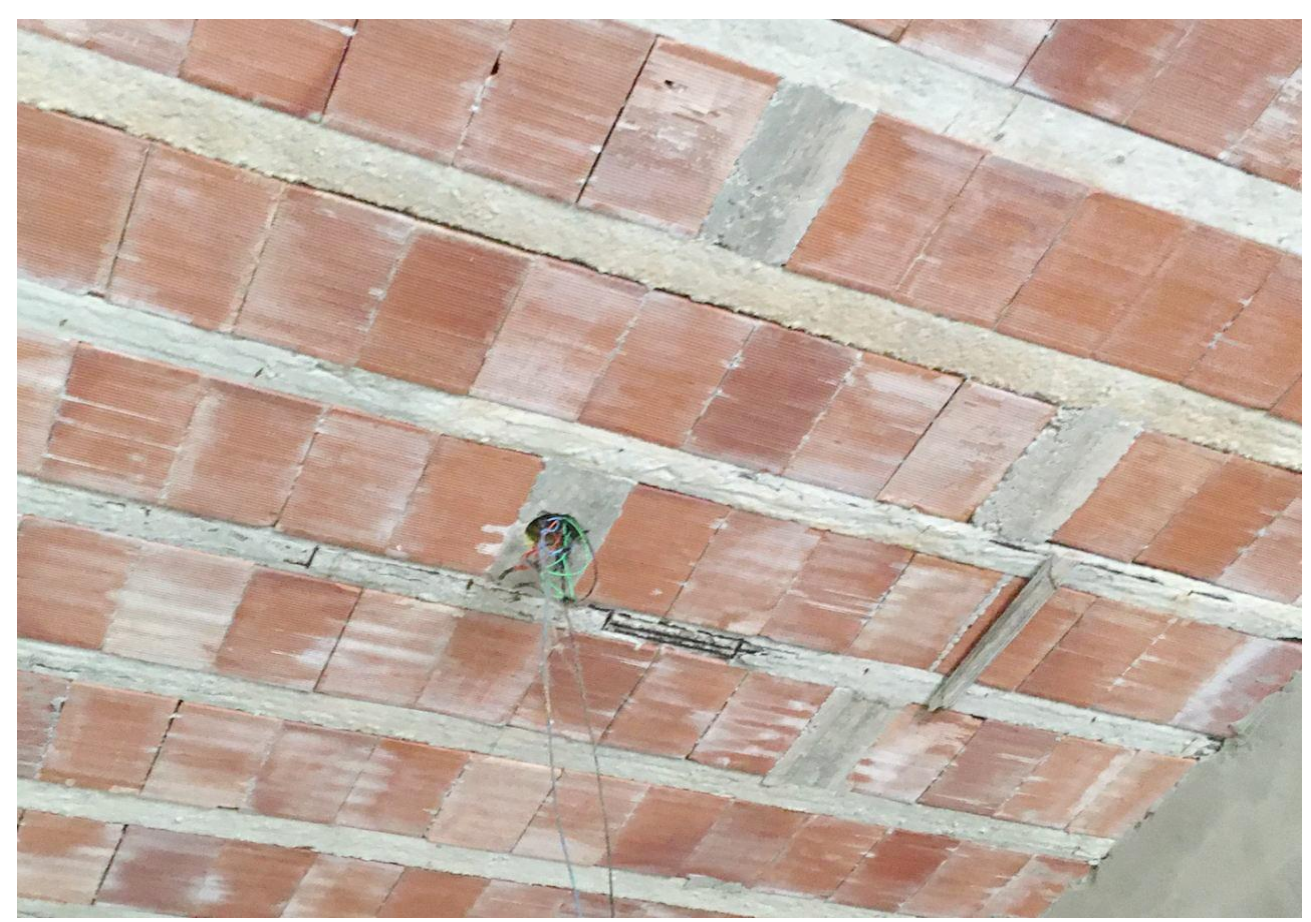

Figura 2 - Laje 102 


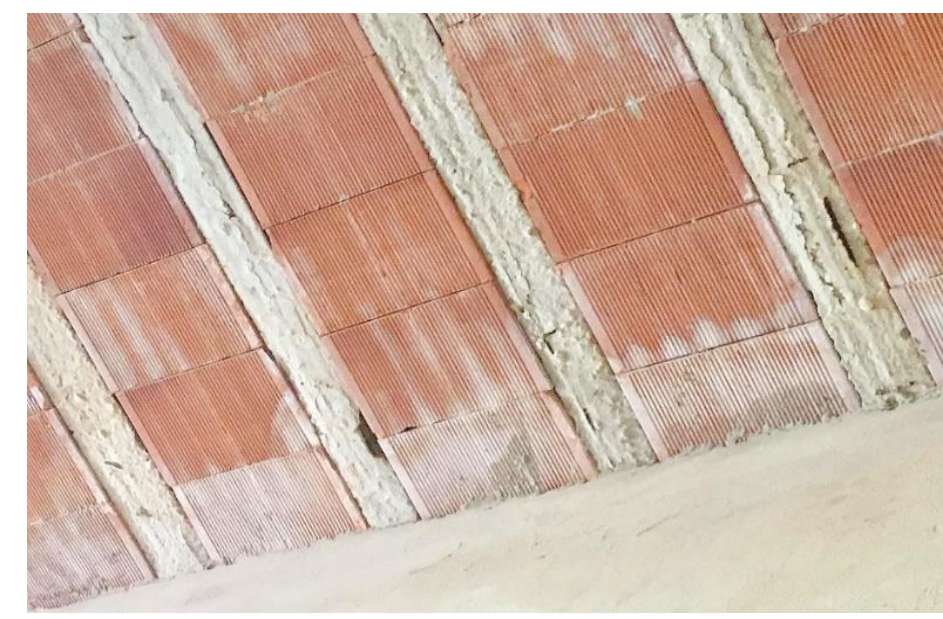

Figura 3 - Desagregação do concreto e corrosão da armação na laje 102

\subsection{Fissuras}

Fissuras são rupturas na superfície do concreto ocasionadas pelo excesso de cargas sobre a estrutura, erros de execução, recalque das fundações, dentre outros. Este tipo de patologia afeta de forma significativa a estabilidade estrutural, a estética e a durabilidade da estrutura, além de facilitar a entrada de agentes agressivos que podem prejudicar a armadura de elementos estruturais.

Na estrutura da residência analisada foi possível observar a presença de fissuras nas vigas. Para a obtenção das medidas referentes às aberturas das fissuras nesses elementos, utilizou-se um fissurômetro. As medidas encontradas estão apresentadas no Quadro 1.

Quadro 1 - Medidas das fissuras

\begin{tabular}{|c|c|c|c|c|c|c|c|}
\hline Vigas & V111A & V111B & V111C & V111D & V112A & V112B & V112C \\
\hline Fissura $(\mathrm{mm})$ & 0,30 & 0,30 & 0,30 & 0,20 & 0,40 & 0,30 & 0,30 \\
\hline
\end{tabular}

De acordo com a NBR 6118/2014, para elementos expostos em ambiente urbano, as fissuras são consideradas agressivas quando a sua abertura ultrapassa 0,30 mm. Portanto, a viga V112A possui fissuras consideras agressivas. A principal causa dessa patologia nesses elementos foi a má execução, ocasionada pela falta de acompanhamento de um profissional qualificado.

Para o caso em estudo haviam, ainda, fissuras nos pilares, alvenarias e na região superior das lajes, ocasionadas pela exposição às chuvas e à radiação solar, provocando dilatações e contrações diárias nesses elementos estruturais, como mostrado nas Figuras 4 e 5.

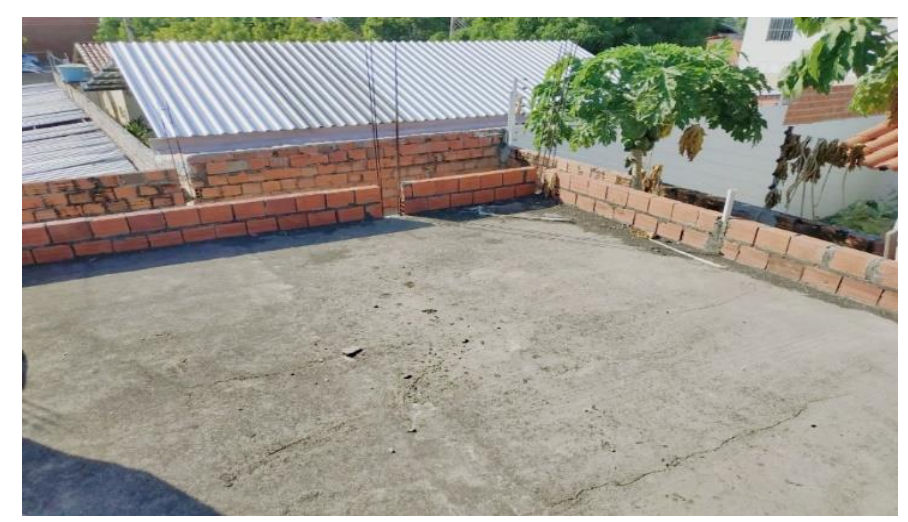

Figura 4 - Fissuras na região superior das lajes 


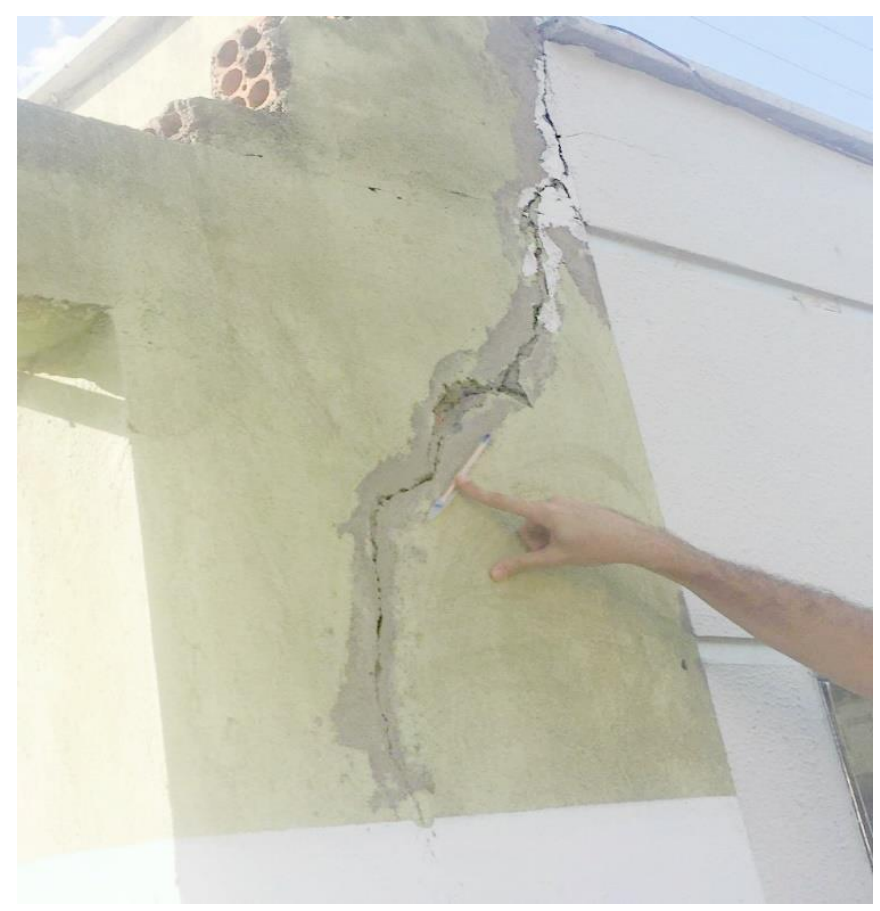

Figura 5 - Fissuras na fachada

\subsection{Infiltração}

A infiltração corresponde ao processo em que a água atravessa a superfície de um determinado material. Nas estruturas de concreto armado, essa manifestação patológica provoca carbonatação do concreto, corrosão da armadura, eflorescências provenientes da lixiviação do concreto, entre outros. Essa patologia possui o maior nível de incidência na residência, uma vez que foi observada em todos os elementos estruturais da edificação, assim como nos elementos de composição arquitetônica, como exemplificado na Figura 6.

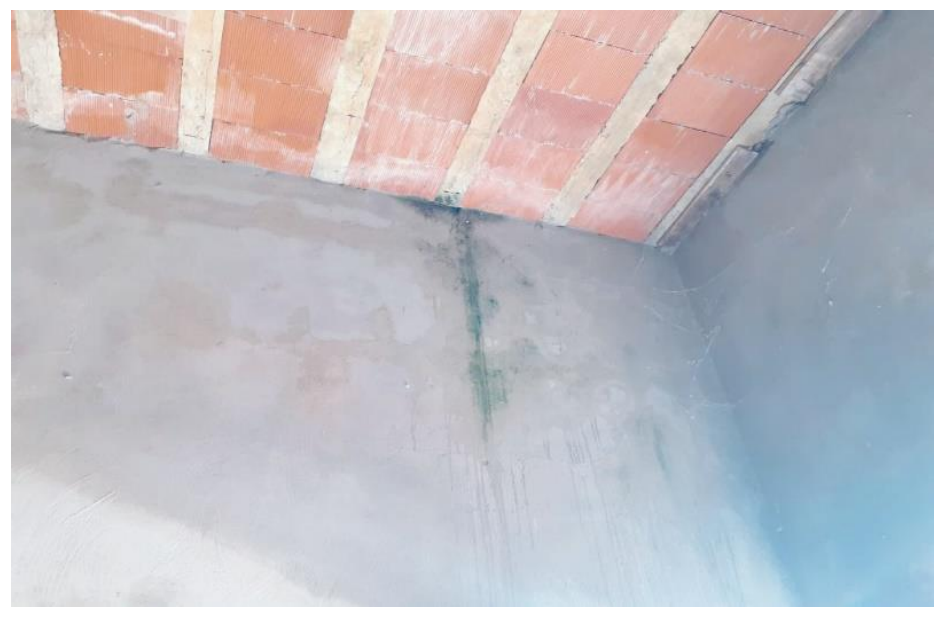

Figura 6 - Infiltração na conexão laje-viga

\subsection{Mofo}

O mofo e água presentes no forro e alvenaria, como mostrado nas Figuras 7 e 8 , são resultados da insuficiência de ventilação e iluminação, assim como do alto teor de umidade presente nas paredes e elementos da residência. Além disso, a ausência do sistema de drenagem de águas pluviais agravou a infiltração na estrutura global, causando desconforto visual e comprometendo drasticamente a segurança dos moradores. 


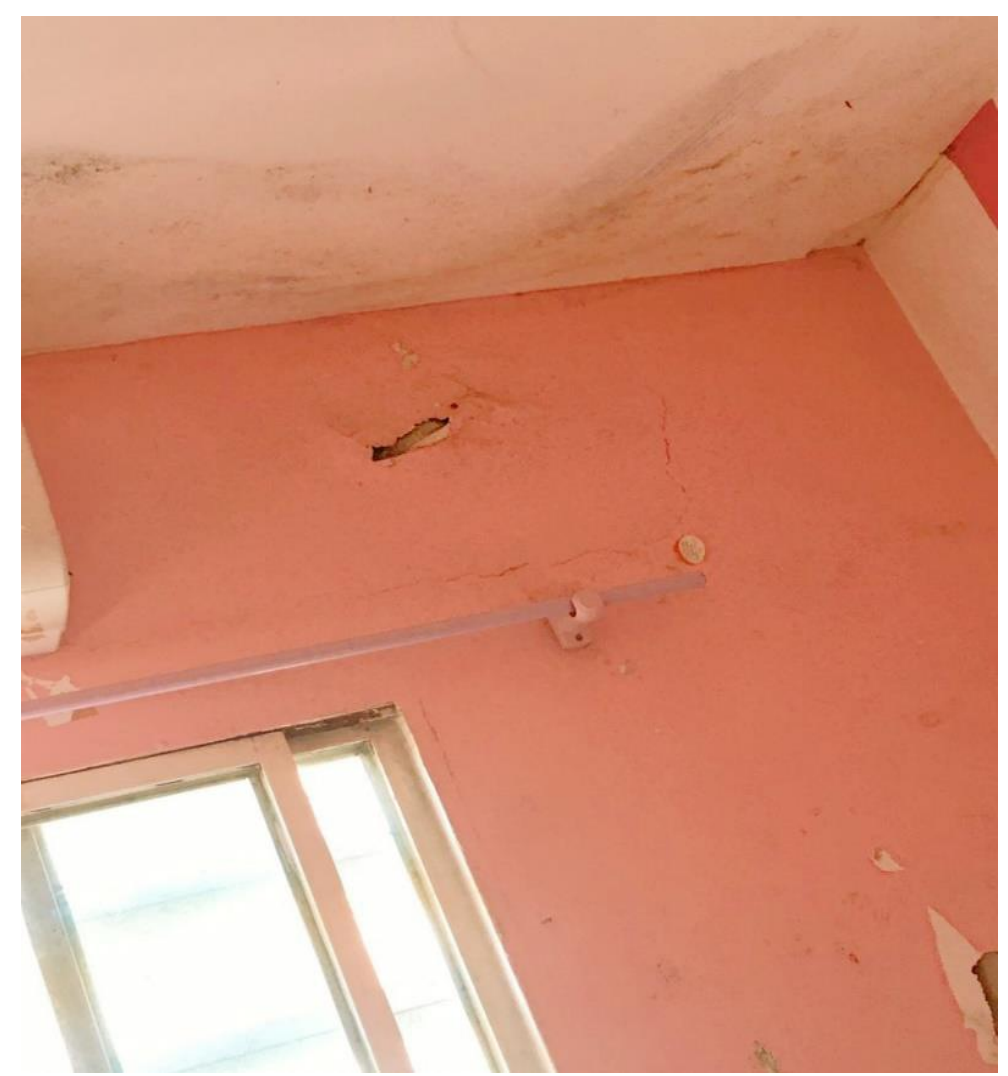

Figura 7 - Mofo, fissuras e infiltração no forro e alvenaria

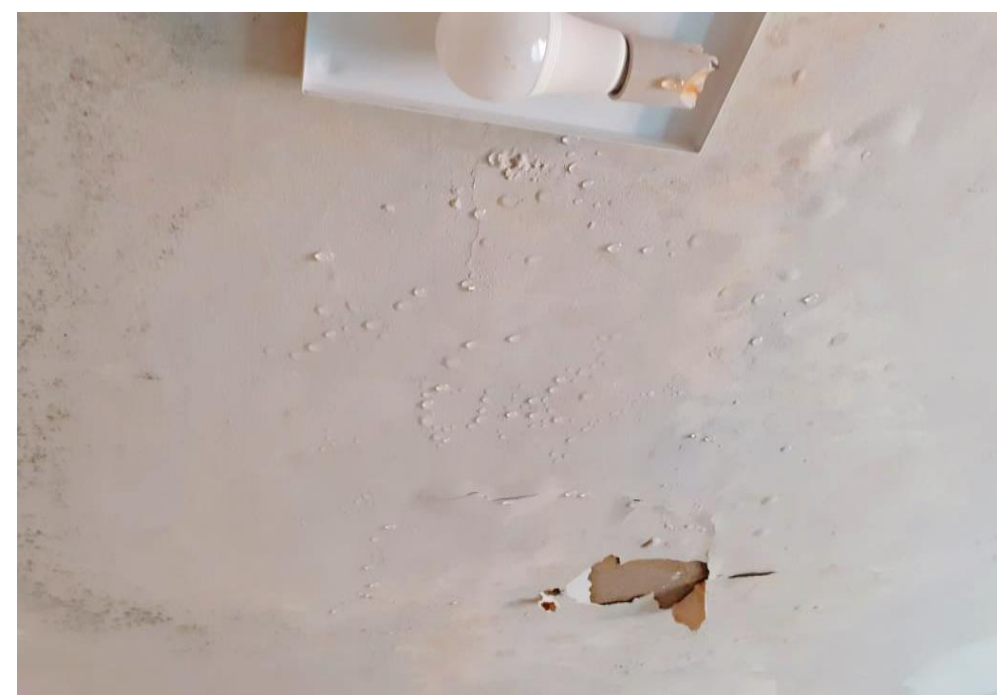

Figura 8 - Mofo e infiltração no forro

\section{Resultados}

Para o cálculo do Grau de Deterioração dos Elementos, a edificação foi dividida em 3 famílias de elementos estruturais (lajes, vigas e pilares), para as quais foram atribuídos fatores de ponderação (Fp), que medem o nível de relevância, e fatores de intensidade (Fi), que medem o nível de severidade dos danos existentes em cada família. Em seguida, foram calculados o grau de dano (D), com o objetivo de determinar a manifestação da patologia em cada peça, o grau de deterioração do elemento isolado (Gde) e, por fim, determinou-se o nível de deterioração para cada um deles. Após a realização desse procedimento de cálculo, os resultados obtidos estão apresentados nos Quadros 2, 3 e 4. 
Quadro 2-Grau de deterioração das lajes

\begin{tabular}{|c|c|c|}
\hline Elemento & $\begin{array}{c}\text { Grau de Deterioração do } \\
\text { Elemento (Gde) }\end{array}$ & $\begin{array}{c}\text { Nível de } \\
\text { deterioração }\end{array}$ \\
\hline $\begin{array}{c}\mathrm{L} 101=\mathrm{L} 103=\mathrm{L} 104=\mathrm{L} 105=\mathrm{L} 106 \\
=\mathrm{L} 107=\mathrm{L} 108\end{array}$ & 15,81 & Médio \\
\hline $\mathrm{L} 102$ & 131,12 & Crítico \\
\hline
\end{tabular}

Quadro 3-Grau de deterioração das vigas

\begin{tabular}{|c|c|c|}
\hline Elemento & $\begin{array}{c}\text { Grau de Deterioração do } \\
\text { Elemento (Gde) }\end{array}$ & $\begin{array}{c}\text { Nível de } \\
\text { deterioração }\end{array}$ \\
\hline $\mathrm{V} 101=\mathrm{V} 102$ & 0 & Baixo \\
\hline $\begin{array}{c}\mathrm{V} 103=\mathrm{V} 104=\mathrm{V} 106=\mathrm{V} 107= \\
\mathrm{V} 108=\mathrm{V} 109=\mathrm{V} 110=\mathrm{V} 111\end{array}$ & 20 & Médio \\
\hline $\mathrm{V} 105=\mathrm{V} 112$ & 96 & Sofrível \\
\hline
\end{tabular}

Quadro 4-Grau de deterioração dos pilares

\begin{tabular}{|c|c|c|}
\hline Elemento & $\begin{array}{c}\text { Grau de Deterioração do } \\
\text { Elemento (Gde) }\end{array}$ & $\begin{array}{c}\text { Nível de } \\
\text { deterioração }\end{array}$ \\
\hline $\begin{array}{c}\mathrm{P} 7=\mathrm{P} 10=\mathrm{P} 11=\mathrm{P} 14=\mathrm{P} 15=\mathrm{P} 16 \\
=\mathrm{P} 20\end{array}$ & 20 & Médio \\
\hline $\begin{array}{c}\mathrm{P} 1=\mathrm{P} 2=\mathrm{P} 3=\mathrm{P} 4=\mathrm{P} 5=\mathrm{P} 6=\mathrm{P} 8 \\
=\mathrm{P} 9=\mathrm{P} 12=\mathrm{P} 13=\mathrm{P} 17=\mathrm{P} 18= \\
\mathrm{P} 19\end{array}$ & 30 & Médio \\
\hline
\end{tabular}

A partir dos resultados presentes nos Quadros 2,3 e 4, observou-se que alguns elementos apresentaram nível de deterioração preocupante (sofrível ou crítico). Para os elementos em estado sofrível, é recomendável planejar intervenção em curto prazo (no máximo em 6 meses), enquanto para o elemento em estado crítico, é recomendável realizar inspeção especial emergencial, assim como intervenção imediata. Para os elementos com nível de deterioração baixo, por sua vez, recomenda-se apenas a realização de manutenção preventiva e para os elementos com nível de deterioração médio, é necessário planejar uma intervenção a longo prazo (no máximo em 2 anos).

\section{Conclusões}

Após a análise dos projetos arquitetônico e estrutural e do acervo fotográfico, foi possível identificar as principais patologias existentes na residência. Nas lajes, as manifestações patológicas existentes são: infiltrações, fissuras, cobrimento insuficiente, desagregação do concreto e corrosão da armadura. Nas vigas e pilares, por sua vez, foram encontradas infiltrações e fissuras e nos elementos de composição arquitetônica (alvenarias de vedação e forros) foram identificadas fissuras, infiltrações e a presença de mofo.

A partir da realização de estudos a respeito das patologias da construção e da coleta de informações relacionadas à execução da residência, foi possível listar as causas para cada uma das manifestações patológicas encontradas. A infiltração de água na estrutura da edificação foi ocasionada pela ausência de sistema de drenagem nas lajes e/ou impermeabilização inadequada desses elementos, além da ausência de telhado com beiral, o que impossibilita a proteção das fachadas contra chuvas.

A presença de fissuras, desagregação do concreto, falta de cobrimento suficiente, exposição e corrosão das armaduras, por sua vez, foram ocasionados por conta dos erros de execução cometidos durante a fase construtiva, a qualidade duvidosa dos materiais e a ausência de manutenção preventiva. Além disso, as fissuras encontradas nas alvenarias também estão relacionadas com a ausência de vergas e/ou contravergas 
nas aberturas das portas e janelas, o que provoca a concentração excessiva de cargas nos vértices das aberturas, gerando trincas e fissuras nesses locais.

Portanto, é possível concluir que a estrutura da edificação atingiu o Estado Limite de Serviço (ELS), uma vez que a presença das manifestações patológicas e o nível de deterioração causado por elas, principalmente na laje 102 da sala de estar e nas vigas que a sustentam, afetaram significativamente o conforto dos moradores, a aparência e a boa utilização da estrutura.

\section{Referências bibliográficas}

ASSOCIAÇÃO BRASILEIRA DE NORMAS TÉCNICAS - ABNT (2014). NBR 6118: Projeto de estruturas de concreto - Procedimento. Rio de Janeiro, 2014, 238 p.;

Boldo, P. (2002). Avaliação quantitativa de estruturas de concreto armado de edificações no âmbito do Exército Brasileiro. Dissertação de mestrado. Faculdade de Engenharia, Universidade de Brasília, 2002;

Castro, E. K. (1994). Desenvolvimento de metodologia para manutenção de estruturas de concreto armado. Dissertação de mestrado. Faculdade de Engenharia, Universidade de Brasília, 1994;

Costa, H. O. (2016). Avaliação de patologias emo bras de arte especiais utilizando a metodologia GDE/UnB. Trabalho de conclusão de curso. Faculdade de Engenharia, Centro Universitário de Brasília, 2016;

De Sitter, W. R. (1984). Costs of service life optimization "The Law of Fives". CEB-RILEM Workshop on Durability of Concrete Structures (Copenhagen, Denmark, May 18-20, 1983). Comité Euro-International du Béton, p. 131-134. 1984;

Fonseca, R. P. (2007). A estrutura do Instituto Central de Ciências: Aspectos históricos, científicos e tecnológicos de projeto, execução, intervenções e propostas de manutenção. Dissertação de mestrado. Faculdade de Engenharia, Universidade de Brasília, 2007;

Gonçalves, E. A. B. (2015). Estudo de patologias e suas causas nas estruturas de concreto armado de obras de edificações. Trabalho de conclusão de curso. Faculdade de Engenharia, Universidade Federal do Rio de Janeiro, 2015;

Gonçalves, M. D. O. (2011). Marquises de concreto armado da cidade de Viçosa-MG: Manifestações patológicas, inspeção e avaliação de grau de deterioração. Dissertação de mestrado. Faculdade de Engenharia, Universidade Federal de Viçosa, 2011;

Lopes, B. A. R. (1998). Sistemas de manutenção predial para grandes estoques de edifícios: estudo para inclusão do componente estrutura de concreto. Dissertação de mestrado. Faculdade de Engenharia, Universidade de Brasília, 1998;

Melo, L. F. D. S. (2020). Análise das manifestações patológicas da Igreja do Santíssimo Sacramento situada na cidade de Arapiraca-AL. Trabalho de conclusão de curso. Faculdade de Engenharia, Universidade Federal de Alagoas, 2020;

Mokdissi Neto, E. H. (2015). Avaliação quantitativa e qualitativa das manifestações patológicas de um edifício residencial no Distrito Federal: estudo de caso. Trabalho de conclusão de curso. Faculdade de Engenharia, Centro Universitário de Brasília, 2015;

Pinheiro, L. P.; Klamt, R. A. (2017). Análise de Manifestações Patológicas em Edificações da Cidade de Rodeio Bonito/RS - Estudo de Caso. Revista de Engenharia, Computação e Tecnologia, v. 01, n. 01, p. 53-58, novembro, 2017;

Rostam, S. (1991). Durability of concrete structures-The CEB-FIP approach. Colloquium on the CEB-FIP MC90, Rio de Janeiro, RJ. p. 369-429. 1991;

Silva, J. Í. P. D. (2019). Determinação do grau de deterioração em uma edificação da Universidade Federal Rural do Semi Árido através da aplicação do método GDE/UNB. Trabalho de conclusão de curso. Faculdade de Engenharia, Centro Universitário de Brasília, 2019. 